\title{
"Chemtrails" in the Sky: Toward a Group-mediated Delusion Theory
}

\author{
Philemon Bantimaroudis ${ }^{1}$ \\ ${ }^{1}$ Dept. of Cultural Technology and Communication, University of the Aegean P.O. Box 108, Mytilene, Greece \\ Correspondence: Philemon Bantimaroudis, Dept. of Cultural Technology and Communication, University of the Aegean
}

P.O. Box 108, Mytilene, Greece.

Received: June 7, 2016 Accepted: June 22, $2016 \quad$ Online Published: July 6, 2016

doi:10.11114/smc.v4i2.1719

URL: http://dx.doi.org/10.11114/smc.v4i2.1719

\begin{abstract}
This case study proposes the concept of group-mediated delusion as a social media related phenomenon. A group-mediated delusion is defined as a jointly held unverifiable view or belief, which a group enforces and sustains through public discussions and persuasion in social media community environments. This study focuses on the "chemtrails" conspiracy theory using descriptive data gathered from Facebook and the Google Trends service. The study concludes that the "chemtrails" notion was enhanced by virtual groups/communities on social media. Google Trends evidence shows an increasing global interest from 2004 until 2015, while most of the Facebook groups were established from 2010 until 2015. The study discusses several implications related to group-mediated delusions.
\end{abstract}

Keywords: chemtrails, group-mediated delusion, conspiracy, virtual community

\section{Introduction}

Losing touch with reality is not uncommon for individuals. A vast array of evidence, derived primarily from the field of psychology testifies in regards to individuals who, at different points in their lives, and with varying levels of intensity, become delusional. "A delusion is a false belief which is firmly sustained and based on incorrect inference about reality. This belief is held despite evidence to the contrary and is not accounted for by the person's culture or religion." This widely accepted definition by psychologists and psychiatric specialists describes different types of delusional disorders observed in individuals.

On the other hand, collective delusions - a group or a community of people holding the same false or unverifiable belief - have been difficult to ascertain. This paper explores the phenomenon of group delusions in relation to social media influences. In the past, media historians and communication theorists have explored a limited stream of empirical evidence derived from the early days of electronic media. Johnson (1952) investigates such a case in Mattoon, Illinois, reporting an incident involving a 'phantom anesthetist' who supposedly was prowling the city. A few other examples are available from those days. The extremely talented radio broadcaster and film director Orson Welles succeeded in his effort to scare his radio audience; almost one million people believed that a Martian invasion was underway in New York City on October 30, 1938. This case of mass paranoia subsequently led to one of the early studies in mass communication effects, carried out by the sociologist Howard Cantril (Lowery \& DeFleur, 1995). Among a handful of documented group or mass delusions in the twentieth century, Medalia and Larsen (1958, p. 180) conducted a case study on "the windshield pitting epidemic that broke out in Seattle, Washington, in the spring of 1954." Initially, local newspapers offered contradictory stimuli to their readers, covering this bizarre incident as a case of vandalism, while later on, "as police were unable to discover evidence of vandalism,..., the news emphasis changed to the theme of 'mystery'" (Medalia \& Larsen, 1958). The public quickly followed this shift in media framing. The researchers argued that certain segments of the local community were more susceptible to becoming delusional than others while reaching similar findings to those of Howard Cantril's invasion from Mars study (Lowery \& DeFleur, 1995).

\subsection{Rationale for the Current Study}

The current case study emerged from informal classroom and corridor discussions with students. Progressively, it became subject to observation that many people adopt different types of available information at face value with relative ease. It was particularly surprising that educated young people displayed a noticeable orientation toward web-generated conspiracism which became manifested in public discussions, especially in relation to certain topics. Upon further inquiry about the origin of the available conspiratorial content, many students pointed out that social 
media communities and certain blogs attract people's interest on these topics. Among other themes, discussions about "chemtrails" - the notion that commercial aircraft spray chemical substances on unsuspecting populations as a part of a global conspiracy to keep people subdued -- have reached significant levels of attention among university students. It was noticed that many educated people held this particular belief while displaying an assurance in regards to the validity of the "chemtrails" conspiracy. When asked about concrete and verifiable evidence for this idea, they often cited sources from social media settings, different websites and blogs. As this was further explored, it became apparent that the "chemtrails" notion does not register as a mainstream media agenda setting influence. Upon searching the entire New York Times database, only two articles related to "chemtrails" were traced. A similar search in the Washington Post database and the CNN website yielded a total of 8 and 1 articles respectively. It seems that global mainstream media have largely ignored this obscure phenomenon, while professional journalists treat this as a paranormal perception of people with conspiratorial inclinations. The "chemtrails" notion does not seem to be related to an elite media agenda promoted by large media entities, rather it represents a bottom-up approach as virtual communities of individuals gather, survey and circulate information through social media platforms and digital word-of-mouth communication.

Based on those initial assessments, this issue deserves our attention. If indeed mainstream media are not primarily involved in generating dubious content of different types, then media scholars need to consider a series of bottom-up influences on modern audiences. It seems that public segments involved in social media discussions somehow generate specific categories of digital content which subsequently becomes available to wider audiences. As certain groups or virtual communities become active in discussions, this issue of group-mediated delusions needs additional attention.

The implications of the current endeavor can be potentially identified both in the realm of perceptions as well as behaviors. In terms of perceptions, many individuals reveal an understanding of the world through a lens of conspiracism. The extent of such influences by group-mediated messages is only subject to speculation. For example, what is the degree of group-mediated, bottom-up generated information that becomes available exclusively in different social media platforms? What kinds of perceptions do people form because of prior exposure to group-mediated content? What types of behaviors are related to group-mediated information?

If such influences can be assessed, they are of foundational significance, as scholars might recognize new media influences. If indeed such evidence exists, scholars are called to identify social media perceptions and behaviors, arguably leading toward new questions deviating from many established media theories of the past that clearly dealt with top-to-bottom approaches of media effects. Furthermore, this notion of group-mediated influences has many implications for everyday life. For example, how much understanding of the modern complex world is derived from group-mediated interactions in the form of an exchange of thoughts and opinions? To what degree does the average person reach daily decisions and act on them, based on opinions of other people, not on the merit of their expertise or prior experience, but just because their thoughts and opinions are so readily available and accessible by everyone? What is the overall influence of word-of-mouth opinions when this information is not verified through institutional sources of information? And to what extent do those group-mediated ideas diverge from dominant ideas generated from established institutions, such as the mainstream media?

The current small-scale study was developed in the context of such larger concerns, generated in an educational setting. Although it cannot answer foundational questions of global concern due to its limited stream of data, this study aims at scratching the surface of those problems. The main goal is to examine whether some preliminary evidence of exploratory nature is available. And of course, follow-up work is necessary in order to connect different pieces of evidence toward the establishment of a clear linkage between group-mediated content and group-mediated delusions.

\subsection{Literature Review --Group Delusions and Digital Media}

If media historians have traced only a handful of mass/group delusions related to media influences during the 20th century, collective delusions do not register as isolated cases any longer. In the 21 st century, this phenomenon has intensified. Social scientists recognize that the spread of false or unverifiable information across the web - including social media, personal blogs and alternative digital publications - has reached tidal proportions (Mocanu et al., 2015; Bratich, 2004). There is however, some evidence toward the opposite direction. For example, Clarke (2007) argued that the internet has retarded the growth of conspiracy theories. Uscinski and Parent (2014) present time-series evidence in regards to the prevalence of conspiratorial content demonstrating that the highest salience of conspiracy theories has been recorded during the 1950s and the 1960s, while the first decade of the 21 st century is indicative of a low intensity in this matter. However, their study is based on a content analysis of letters to the editor of the New York Times. One could argue that a digital media analysis could have yielded different results.

As a matter of fact, massive volumes of undocumented information reach different segments or virtual communities, most noticeably through word-of-mouth in digital environments of social media services. This phenomenon is under scrutiny as experts accumulate evidence in regards to social media use and the spread of conspiracy theories, a popular 
form of group delusions. ${ }^{2}$ Furthermore, communities have evolved in the digital world and are defined in different ways, depending on scholarly operational definitions and public applications. Researchers agree that virtual communities are relatively new and unexplored social structures, as scientists often refer to "groups of people who communicate with each other via electronic media" (Romm, Pliskin \& Klarke, 1997). Communities are no longer subject to geographical or space constraints that define how different segments of the public coexist and interact with one another. Often scholars use the term "virtual community" in order to explain a social coexistence through the use of technology. Romm, Pliskin and Klarke (1997) describe three types of variables that need consideration in terms of virtual communities: "(1) variables that affect individuals' decisions to join virtual communities; (2) variables that explain how members of virtual communities affect their immediate environment; and (3) variables that describe how virtual communities are transforming society." Although communities are characterized by their interaction with a specific digital technology, there are cases where community members engage in multiple media usage that exceeds the use of their primary medium (Sillence \& Baber, 2004).

As researchers survey a multitude of data available on the web, they converge along some basic findings. For example, they agree that conspiracy theorists constitute distinct groups of virtual communities that are exposed to alternative news sources, because they believe that mainstream news outlets are subject to government manipulation and direct influence. Therefore they stay away from standard news outlets while being influenced by alternative media content. Aaronovitch (2009) describes belief in conspiracies as "the attribution of deliberate agency to something that is more likely to be accidental or unintended, therefore it is the unnecessary assumption of conspiracy when other explanations are more probable."

This relationship between people's media choices and their beliefs in conspiracy theories can be speculated on by emerging popular trends, rendering conspiratorial content salient in the public mind. For example, Time correspondent Lev Grossman notes that a significant number of Americans believe that the American Government was implicated in the attack against the US Trade Center on September 11, 2001. Grossman argues that " $36 \%$ of Americans consider it "very likely" or "somewhat likely" that government officials either allowed the attacks to be carried out or carried out the attacks themselves."

Conspiratorial inclinations are evident in a wide array of subjects, not just confined in the fields of politics and international conflict. Popular conspiracy themes include (but are not limited to) airline mysteries (such as the disappearance of Malaysian flight 370), "chemtrails" (a popular conspiracy theory related to the belief that aircrafts are used to spray populations with chemicals with the intent of keeping people under control), and a web-driven global anti-vaccination movement, discouraging parents from vaccinating children under the assumption that vaccines are a part of a global conspiracy for population control.

Researchers have focused on different groups and their strongly held assumptions. For example, Zook (1996) examined the case of the so-called unorganized American militia movement and its relationship with computer-mediated communication. In his study he demonstrates the effectiveness of virtual communities in establishing and sustaining the legitimacy of such views. He argues that mediated networks of such groups are quite successful as they (a) provide alternative information sources, (b) legitimize their own media sources as credible and trustworthy, (c) create greater access to mainstream public segments, (d) reduce isolation and (e) sustain communication channels between de-centralized groups and individuals. Porter and Hellsten (2014) identify social, instrumental and technological determinants of activism through social media. Although they argue that the ability of social media groups to mobilize toward a political objective is debated among scholars, they point to evidence which is relevant to the current work, as marginalized groups have the capacity to challenge mainstream beliefs. Wood et al (2012) converge with Zook (1996) while arguing that "spurred in part by the growth of new media, conspiracism has become a major subcultural phenomenon." Their findings provide useful evidence of the growth of conspiratorial views as digital media have proliferated across the globe. If $9 / 11$ and the militia movement represent two established streams of conspiratorial material, such views can be circulated in the most unlikely digital routes - e.g. websites providing parental advice for children's health care. In a case study on the social acceptance of vaccination, Kata (2010) makes some profound observations on the problem of group-mediated delusions. She argues that social media and alternative media outlets play a pivotal role as they sensationalize people's objections in regards to vaccination. This dissemination of laypeople's arguments creates an 'anti-vaccination movement' influencing both individual and collective decisions. Consequently, communication technology enhances people's exposure to arguments about risks related to vaccination while empowering a rhetoric leading to doubt and fear. "Parents incorporate this with personal experiences and spread their views to the social groups. These social groups exert considerable pressure on vaccination decisions by creating a 'local vaccination culture" (Kata, 2010). 


\subsection{Research Questions}

Thereby the following research questions were deemed appropriate:

RQ1: What is the extent of people searching for the "chemtrails" conspiracy using the Google search engine?

RQ2: What is the extent of "chemtrails" groups/communities being present on Facebook?

RQ3: Is there any observable relationship between group Facebook presence and Google searching for the chemtrails" conspiracy?

These are exploratory questions which seek to descriptively assess the presence of this subcultural phenomenon on social media and search engines.

\section{Method}

A case-study approach was selected because of the exploratory nature of this study. The main objective of this project is to trace the "chemtrails" conspiracy as a group- mediated notion and to assess its salience among its members. For the purpose of this case study, a group-mediated delusion was defined as: a jointly held unverifiable view or belief, which groups enforce and sustain through public discussions and persuasion in digital media community environments. The "chemtrails" trend is described in numerous websites of questionable credibility. "According to the chemtrail conspiracy theory, long-lasting trails left in the sky by high-flying aircraft are chemical or biological agents deliberately sprayed for sinister purposes undisclosed to the general public." ${ }^{.4}$ Initially, the current study has the aim of identifying group-mediated content on social media and assessing the level of interest toward this topic. This is a necessary research stage prior to identifying connections between group-mediated information and group-mediated influences - in this case group delusions. Thereby, the first two questions constitute initial steps toward the establishment of this case. The third question attempts a preliminary connection between content and influences without though the necessary volume of data that would establish such a linkage. Hopefully, future studies will benefit from rich datasets and different control variables.

Empirically documenting the extent of this phenomenon will be revealing of group-mediated trends as social media increasingly acquire the status of information gatekeepers, while claiming the role of alternative journalism. This trend has numerous implications in regards to people's perceptions and perhaps behaviors while alternative sources of "information" set agendas for different segments around the world. Data were gathered from the following sources:

"Chemtrails" in the Google Trends Service: To assess the degree of people searching for "Chemtrails", the Google Trends service was deemed an appropriate tool as it documents public searching trends in the Google search engine from users around the world. Furthermore, it provides longitudinal data on a monthly basis. For the purpose of this study, it is argued that searching on line for "chemtrails" constitutes a form of public attention, as people seek information perceived as significant. The key issue here is individuals or groups of individuals seeking particular information about a dubious topic without a dominant agenda set by mainstream media. Google Trends also provides comparative searching patterns, allowing the researcher to assess the volume of searching from different parts of the world. Ripberger (2011) conducted an extensive empirical study to assess the validity of Google Trends as a measure of public salience, drawing from research on epidemiology. The study concluded that there is considerable potential for researchers as such innovative measures allow scientists "to refine and test theories of public attention that have up until now been hindered by data deficiencies" (Ripberger, 2011). For every search, Google Trends provides monthly data on a proportional scale from 0 to 100 , where 100 indicates the month with the highest searching activity. This variable provides an index of "chemtrails" searching activity on a monthly basis, from January 2004 until June 2015. All available data provided by the Google Trends platform were utilized in the current study. Since this case study was conducted on June 2015, the Google Trends service provided data for eleven years, from January 2004 until June 2015.

Chemtrails on Facebook: To investigate the presence of "chemtrails" related groups/communities on Facebook, the platform was searched for different communities. Once a Facebook site/community was located, several characteristics became subject to observation, such as the starting date of the site, the purpose of the community, its link with other websites, its mission statement and the number of "likes" posted on the Facebook site. This information is indicative of the type and size of public segments that look for such content and might hold "conspiratorial" beliefs. As the platform was searched, all available "chemtrails" communities were identified and scrutinized.

\section{Results}

To answer the research questions, the use of descriptive statistics was deemed adequate for the current case study. Thereby, no inferential measures were utilized. A preliminary descriptive analysis of the Google Trends service shows a steady increase of people searching for "chemtrails." Google provides an index of searching trends on a relative scale from 0 to 100, where 100 represents the highest volume of searching during the entire period. All other scores are 
relative to the highest score. Based on that scale, during the 11,5 year period of this study, the average score was 43 , with a standard deviation of 16,3 .

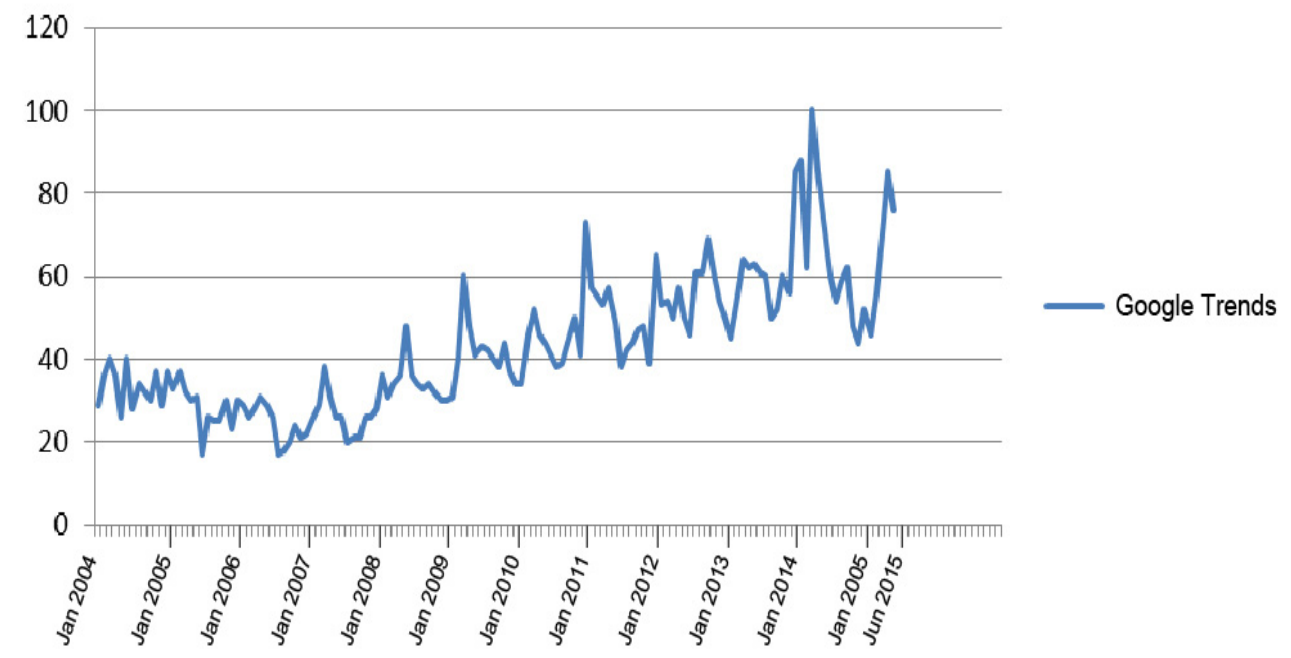

Graph 1. Google Users Searching for "Chemtrails" (January 2004 - June2015)

The highest score (100) was recorded on April 2014, indicative of a strong recent public interest in the "chemtrails" conspiracy theory. To enhance our understanding of mean fluctuations over the entire 11,5-year period, time was divided equally in two periods, each one comprised of 69 months. Indeed, the t-test yielded statistically significant differences in mean scores between the two time periods.

Table 1. Mean Differences in Google Trends Scores in two time periods

\begin{tabular}{lc}
\hline Time & Average Google Trends Score \\
\hline January 2004 - September 2009 & 31,02 \\
October 2009 - June 2015 & 54,98 \\
T-test $=-13,218$ & Google Trends Scale: 1 - 100 \\
Df $=68$ & \\
$\mathrm{P}<0.0001$ & \\
\hline
\end{tabular}

From January 2004 until September 2009, the average Google Trends score was 31,02, while during the second period (October 2009 - June 2015), the Google Trends mean score was 54,98. There is a clear upward trend in the intensity of people searching Google for "chemtrails" after 2009, while reaching the highest volume in 2014. The data indicate more intense fluctuations during the latter period (October 2009 - June 2015) as the standard deviation registers at 13,56, in contrast to smaller fluctuations during the early period (January 2004 - September 2009) with the standard deviation at 7,74. Based on this descriptive analysis, there is evidence of increased recent interest at varied levels from 2009 until 2015.

The second exploratory research question deals with the presence of "chemtrails" groups/communities on the Facebook platform. The search on Facebook yielded more than one hundred results, including individuals and communities, indicative of a substantial interest in the "chemtrails" notion. After surveying these various Facebook communities, this study focused on 38 sites, specifically using the term "chemtrails" while explicitly describing the phenomenon. Furthermore, communities were identified by their mission statement and description, but additional scrutiny was paid to popular communities defined by at least 500 likes. The main emphasis of the current endeavor is on group or community formations and, thereby, trivial presence on Facebook without a significant number of followers was not deemed worthy of scrutiny. A brief survey of the aforementioned "Chemtrail" groups shows that participants often employ a scientific language - such as references to geoengineering - in order to establish the legitimacy of their arguments. Table 2 presents evidence acquired from the Facebook platform in terms of the most significant "chemtrails" communities. 
Table 2. "Chemtrails" Groups on Facebook

\begin{tabular}{|c|c|c|c|c|}
\hline Facebook "Chemtrails" Community/Group & Title & Starting Date & $\begin{array}{l}\text { Group } \\
\text { members }\end{array}$ & «Likes» \\
\hline $\begin{array}{l}\text { https://www.facebook.com/pages/Chemtrails-Awar } \\
\text { eness/12282631069 }\end{array}$ & Chemtrails Awareness & & - & 48,288 \\
\hline https://www.facebook.com/ChemtrailsGalicia & Chemtrails Galicia & May 8,2012 & & 4,249 \\
\hline $\begin{array}{l}\text { https://www.facebook.com/pages/Chemtrails-Mala } \\
\text { ga/333392076870232 }\end{array}$ & Chemtrails Malaga & & & 803 \\
\hline https://www.facebook.com/ChemtrailsGreece & Chemtrails Greece & & & \\
\hline https://www.facebook.com/chemtrailss & $\begin{array}{l}\text { Знаят ли българите } \\
\text { какво е Chemtrails и } \\
\text { колко e опасно за } \\
\text { хората? }\end{array}$ & May 1,2011 & & 18,189 \\
\hline https://www.facebook.com/chemtrails.argentina.9 & Chemtrails Argentina & & & 3,600 \\
\hline https://www.facebook.com/ChemtrailsProjectUK/ & Chemtrails Project UK & $\begin{array}{l}\text { December 21, } \\
2011\end{array}$ & & 7,837 \\
\hline $\begin{array}{l}\text { https://www.facebook.com/groups/1955598339072 } \\
\text { 53/ }\end{array}$ & Closed Group & & 2,858 & \\
\hline $\begin{array}{l}\text { https://www.facebook.com/groups/chemtrailsarekill } \\
\text { ingus/ }\end{array}$ & $\begin{array}{l}\text { Chemtrails are killing } \\
\text { up } \\
\text { Closed group }\end{array}$ & & 4,561 & \\
\hline $\begin{array}{l}\text { https://www.facebook.com/groups/ChemtrailOester } \\
\text { reich/ }\end{array}$ & Closed Group & & 1,333 & \\
\hline $\begin{array}{l}\text { https://www.facebook.com/ChemtrailsGeoengineer } \\
\text { ingFrance }\end{array}$ & Chemtrails France & April, 2015 & & 1,656 \\
\hline $\begin{array}{l}\text { https://www.facebook.com/pages/Chemtrails-Devo } \\
\text { n/302211039897080 }\end{array}$ & Chemtrails Devon & $\begin{array}{l}\text { November, } \\
2012\end{array}$ & & 914 \\
\hline $\begin{array}{l}\text { https://www.facebook.com/pages/Chemtrails-Sydn } \\
\text { ey/179511132146169?sk=info }\end{array}$ & Chemtrails Sydney & & & 2,079 \\
\hline $\begin{array}{l}\text { https://www.facebook.com/pages/Stop-Chemtrails/ } \\
330176123695801\end{array}$ & Stop Chemtrails & $\begin{array}{l}\text { February } \\
2012\end{array}$ & & 9,360 \\
\hline https://www.facebook.com/chemskyireland.cky & Chemtrails Ireland & & & 731 \\
\hline $\begin{array}{l}\text { https://www.facebook.com/GlobalMarchAgainstCh } \\
\text { emtrailsAndGeoengineering }\end{array}$ & $\begin{array}{lr}\text { Global } & \text { MARCH } \\
\text { Against } & \text { Chemtrails } \\
\text { and Geoengeneering }\end{array}$ & June 2, 2013 & - & 29,228 \\
\hline $\begin{array}{l}\text { https://www.facebook.com/pages/1000000-Against } \\
\text {-ChemTrails/227810860566469 }\end{array}$ & $\begin{array}{l}1,000,000 \quad \text { Against } \\
\text { ChemTrails }\end{array}$ & & & 6,168 \\
\hline https://www.facebook.com/InternationalChemtrail & $\begin{array}{l}\text { International } \\
\text { Chemtrail Association }\end{array}$ & & & 9,701 \\
\hline $\begin{array}{l}\text { https://www.facebook.com/pages/Chemtrails-Suiss } \\
\text { e-Romande/129491020406584 }\end{array}$ & $\begin{array}{l}\text { Chemtrails } \quad \text { Suisse } \\
\text { Romande }\end{array}$ & & & 888 \\
\hline $\begin{array}{l}\text { https://www.facebook.com/pages/Gemeinsam-gege } \\
\text { n-Chemtrails/221320667926914 }\end{array}$ & $\begin{array}{l}\text { Gemeinsam gegen } \\
\text { Chemtrails }\end{array}$ & & & 1,219 \\
\hline $\begin{array}{l}\text { https://www.facebook.com/pages/Chemtrails-A-Wo } \\
\text { rld-Wide-Ban-Now/132692550246388?sk=timeline } \\
\text { \&ref=page internal }\end{array}$ & $\begin{array}{l}\text { Chemtrails - A World } \\
\text { Wide Ban Now }\end{array}$ & March 2013 & & 1,261 \\
\hline $\begin{array}{l}\text { https://www.facebook.com/CaChemtrails/timeline? } \\
\text { ref=page internal }\end{array}$ & CA Chemtrails & & & 10,700 \\
\hline $\begin{array}{l}\text { https://www.facebook.com/StopChemtrailsNadPols } \\
\text { ka }\end{array}$ & $\begin{array}{l}\text { Stop Chemtrails nad } \\
\text { Polską }\end{array}$ & 2012 & & 608 \\
\hline https://www.facebook.com/chemtrailsproject & Chemtrails Project & & & 3,538 \\
\hline https://www.facebook.com/chemtrailresearch & Chemtrail Research & 2011 & & 7,629 \\
\hline https://www.facebook.com/actu.chem & Chemtrails ActuChem & & & 2,251 \\
\hline https://www.facebook.com/ChemtrailsMap & Chemtrails Map & June 10, 2012 & & 2,416 \\
\hline https://www.facebook.com/MurciaChemtrails & Chemtrails Murcia & & & 3,579 \\
\hline https://www.facebook.com/Antenachemtrail & $\begin{array}{l}\text { Chemtrails Antena } \\
\text { Chemtrails }\end{array}$ & & & 4,646 \\
\hline https://www.facebook.com/ChemtrailsLT & Chemtrails Lithuania & & & 1,111 \\
\hline https://www.facebook.com/ChemtrailsPlanet & Chemtrails Planet & & & 1,826 \\
\hline $\begin{array}{l}\text { https://www.facebook.com/pages/Chemtrails-Czec } \\
\text { h-Republic/134186823387005 }\end{array}$ & $\begin{array}{l}\text { Chemtrails } \quad \text { Czech } \\
\text { Republic }\end{array}$ & 2012 & & \\
\hline $\begin{array}{l}\text { https://www.facebook.com/pages/Chemtrails-Portu } \\
\text { gal/122803704425975 }\end{array}$ & Chemtrails Portugal & & & 1,059 \\
\hline https://www.facebook.com/ChemtrailsNews & Chemtrail News & & & 1,206 \\
\hline https://www.facebook.com/ChemtrailsNederland & Chemtrails Nederland & 2012 & & 1,484 \\
\hline $\begin{array}{l}\text { https://www.facebook.com/pages/Chemtrails-Roma } \\
\text { /623010824470655 }\end{array}$ & Chemtrails Roma & & & 2837 \\
\hline $\begin{array}{l}\text { https://www.facebook.com/pages/Chemtrails-Ontar } \\
\text { io/234471153320318 }\end{array}$ & Chemtrails Ontario & 2010 & & 852 \\
\hline $\begin{array}{l}\text { https://www.facebook.com/TurkiyeChemtrailsTaki } \\
\text { pcileri }\end{array}$ & $\begin{array}{l}\text { Türkiye Chemtrails } \\
\text { Takipçileri }\end{array}$ & $\begin{array}{l}18 \text { Mapríov, } \\
2013\end{array}$ & & 12,442 \\
\hline
\end{tabular}

Data collected on June 2015 from www.facebook.com

Two additional indices were searched for in regards to Facebook "chemtrails" groups, namely the starting date - 
indicating the date a group was established - and the number of "likes", a popular term among Facebook users demonstrating how many people like a particular site and its content. A few closed groups indicate the number of participating community members. Most sites were open for anyone desiring to participate.

This descriptive analysis shows that the number of "likes" for different Facebook sites significantly varies from 608 to 48,288 . The total of "likes" for all of the 38 "chemtrail" Facebook sites under scrutiny adds up to a total of 204,355 "likes". While this could be viewed as marginal in light of the 11 million likes posted, for example, in Apple's Application Facebook site, this number is not negligible and it represents a global subcultural phenomenon. As such, the presence of such communities merits additional attention.

Facebook provides information about each site, though not all site managers registered their starting dates. Out of the 38 Facebook communities surveyed in the context of the current study, 15 provide information about their starting date. Based on the available data, it is noteworthy that these communities were established relatively recently, -- between 2010 and 2015 as table 2 indicates.

\section{Discussion}

The current study provides only exploratory evidence of descriptive nature. Although the assembled evidence is indicative of larger subcultural phenomena, such as group-mediated delusions, at this stage, and based on the available information, we argue that additional evidence is needed for the exploration of foundational questions, arguably leading toward new media influences.

Based on evidence derived from the available literature and the data gathered for the current project, it seems that group-mediated information has the capacity of becoming salient without prior coverage by global mainstream media. The fact that the "chemtrails" notion has been largely ignored by mainstream media while it demonstrates significant attention in social media settings is significant on its own. This finding is enhanced by the Google Trends data clearly showing a global interest on the "chemtrails" phenomenon at an increasing rate. In this case study, there is no relation between the media agenda and Google trends as is often the case with other agendas (Ripsberger, 2011). The current study of the Google Trends platform demonstrates an upward trend of users searching for "chemtrails". This is indicative of an increasing global interest and perhaps concern in regards to a perceived conspiracy claiming that unidentified global actors use commercial aircrafts to spray populations with the intent of keeping populations under control. Our Facebook search shows that the establishment of "chemtrails" sites/communities has been particularly noteworthy during the period 2010-2015, when Google searches significantly increased. Although this finding should be approached with caution, Facebook communities and Google searches seem to follow a parallel trail. Therefore, this bottom-up idea -- that groups or communities of individuals can generate information in mediated environments and then spread it to other public segments and potentially other media is supported by the current findings. The increasing trend of Facebook communities discussing this issue in combination with the increasing rate of people searching for this idea is indicative of group capacity to set alternative - perhaps subcultural - agendas without the intervention of established, globally recognized media entities.

What are the implications of the current finding? Is there a clear linkage between the generation of group-mediated information and group-mediated delusions? Can we document a linkage between mediated-group discussions and different forms of digital conspiracism? Furthermore, are current group delusions indeed mediated and group generated? Although the current study does not provide conclusive evidence about those foundational questions, there are clearly indications pointing toward group-mediated delusions.

The surveyed literature identifies some of the core mechanisms that spread unverifiable information among users through mediated word-of-mouth. In such virtual communities: (a) participants cannot assess the validity of different types of information; (b) participants cannot differentiate among different sources of information in terms of their integrity; (c) groups of participants often share common delusional beliefs without any capacity for external verification; (d) group delusions influence different forms of perceptions as well as individual and social behaviors (Kata, 2010). Different researchers argue that the digital world has impacted our social experiences, altering the ways we acquire information, our knowledge processing and building functions, our perceptions of the global environment and even our daily behaviors. Therefore, new theoretical questions should emerge, initiating new investigations pertaining exclusively to the digital social media environment. Isolated studies from the previous century document significant media effects on mass delusions, documented in early communication research. In the digital media context, the literature indicates a growth of group delusions as members of virtual communities acquire easy access to on-line forums and social media. Researchers imply that any notion receiving some exposure on social media can draw followers, while in some cases it can reach the status of a subcultural movement (Neumann, 2013).

The current evidence is indicative of a group/community-mediated delusion. From the current evidence, several issues should be subject to future research: 
Group-mediated delusions seem to be related to social media platforms and word-of mouth practices as previous literature clearly indicates. Therefore, in digital media settings along with established and well researched influences such as agenda setting, researchers should also focus on alternative formations of salience which start with groups of individuals or particular community members investing on word-of-mouth communication for the promotion of content which mainstream media and established gatekeepers would easily filter away and discard.

Group-mediated delusions seem to have an impact on community perceptions as well as behaviors. Previous literature and evidence derived from the current case study indicate a proliferation of different beliefs, not always verifiable through methods of scientific inquiry and external validation. This impact on different people seems to cause not only perceptional alterations but also behavioral changes - such as parents refusing to vaccinate their children because of concerns of a conspiratorial nature (Kata 2010; Alvin Chin et al. 2010).

Media theorists along with specialists from other fields, such as social psychologists and sociologists, should examine various factors that lead to virtual community formation in relation to group delusions. Future research endeavors should examine how social media groups influence group perceptions and behaviors in conjunction with other personality oriented variables that draw certain individuals into these groups/communities. These include: psychological factors such as fear, isolation, endangerment, along with community dynamics such as cultural and socioeconomic parameters. According to Uscinski and Parent (2014), conspiracy theories "tend to resonate when groups are suffering loss, weakness or disunity."

In conclusion, journalism scholars have a vested interest in exploring group-generated information, as such communities compete against mainstream journalism while they establish their own information generation standards for production and dissemination. At the core of future explorations, scholars should examine the role of different digital tools and platforms as they empower individuals and groups in terms of interaction and agenda formation, often leading toward alternate unverifiable group delusions. This development is expected to intensify as digital media proliferate and different groups around the world increasingly exploit the easy access and the legitimized group structure and interaction that such platforms offer. As subcultural groups and alternative views interact, new agendas are expected to compete against mainstream agendas produced primarily by professional journalists and established news organizations. In this context, several research questions might merit future attention: To what extent are alternative sources of group-mediated communication enhancing a multitude of information choices in pluralistic settings? To what extent does alternative group-mediated communication lead toward the production of dubious non-verifiable delusions, conspiratorial in nature, which affect people's perceptions and behaviors with negative consequences for the whole of society? To what extent does group-generated information infringe on journalists' "cultural authority," their power to define realities and affirm hegemonic beliefs and structures of thought (Starr, 1982; Reese, 1990)? In the long run, what does it mean for modern citizens to replace hegemonic beliefs with non-verifiable or delusional perceptions of the world?

In a global social media environment, how do educational institutions train future digital users while investing in their critical thinking tools and methodological understanding as they are called to identify what information is logically ascertainable and what cannot be externally verified? Finally, how has journalism as a profession been affected by group-mediated digital content? The current case study is only exploratory in nature as we need additional data to answer foundational questions. Thus, it is subject to limitations both in terms of the available data and, consequently, the methods that could have been employed to reach conclusive findings. Despite the shortcomings, it serves as an initial body of evidence that might generate a larger discussion.

\section{References}

Aaronovitch, D. (2009). Voodoo histories: The role of the conspiracy theory in shaping modern history. London: Jonathan Cape.

Bratich, Z. (2004). Trust no one (on the internet): The CIA-Crack-Contra conspiracy theory and professional journalism. Television \& New Media, 5(2), 109-139. http://dx.doi.org/10.1177/1527476403255810

Chin, A., Keelan, J., Tomlinson, G., Pavri-Garcia, V., Kumanan, W., \& Chignell, M. (2010). Automated delineation of subgroups in web video: A medical activism case study. Journal of Computer-Mediated Communication, 15(3), 447-464. http://dx.doi.org/10.1111/j.1083-6101.2010.01507.x

Clarke, S. (2007). Conspiracy theories and the internet: Controlled demolition and arrested development. Episteme, 4(2), 167-180. http://dx.doi.org/10.3366/epi.2007.4.2.167

Johnson, D. (1952). The phantom anesthetist of Mattoon. In Guy E. Swanson, T. M. Newcomb \& Eugene H. Hartley (Eds.), Readings in Social Psychology (pp 208-219). New York: Holt.

Kata, A. (2010). A postmodern Pandora's box: Anti-vaccination misinformation on the internet. Vaccine, 28(7), 
1709-1716. http://dx.doi.org/10.1016/j.vaccine.2009.12.022

Lowery, S., \& DeFleur, M. (1995). Milestones in mass communication research: Media effects (3rd Ed.). White Plains, N.Y.: Longman.

Medalia, N., \& Larsen, O. (1958). Diffusion and belief in a collective delusion: The Seattle windshield pitting epidemic. American Sociological Review, 23(2), 180-186. http://dx.doi.org/10.2307/2089002

Mocanu, D., Rossi, L., Zhang, Q., Karsai, M., \& Quattrociocchi, W. (2015). Collective attention in the age of (mis)information. Computers in Human Behavior, 51, 1198-1204. http://dx.doi.org/10.1016/j.chb.2015.01.024

Neumann, P. (2013). Options and strategies for countering online radicalization in the United States. Studies in Conflict \& Terrorism, 36(6), 431-459. http://dx.doi.org/10.1080/1057610X.2013.784568

Porter, A., \& Hellsten, L. (2014). Investigating participatory dynamics through social media using a multideterminant "frame" approach: The case of climategate on YouTube. Journal of Computer-Mediated Communication, 19(4), 1024-1041. http://dx.doi.org/10.1111/jcc4.12065

Reese, S. (1990). The news paradigm and the ideology of objectivity: A socialist at the Wall Street Journal. Critical Studies in Mass Communication, 7(4), 390-409. http://dx.doi.org/10.1080/15295039009360187

Ripberger, J. (2011). Capturing curiosity: Using internet search trends to measure public attentiveness.' The Policy Studies Journal, 39(2), 239-259. http://dx.doi.org/10.1111/j.1541-0072.2011.00406.x

Romm, C., Pliskin, N., \& Clarke, R. (1997). Virtual communities and society: Toward an integrative three phase model. International Journal of Information Management, 17(4), 261270. http://dx.doi.org/10.1016/S0268-4012(97)00004-2

Sillence, E., \& Baber, C. (2004). Integrated digital communities: Combining web-based interaction with text messaging to develop a system for encouraging group communication and competition. Interacting with Computers, 16(1), 93-113. http://dx.doi.org/10.1016/j.intcom.2003.11.007

Starr, P. (1982). The social transformation of American medicine. New York: Basic Books.

Uscinski, J., \& Parent, J. (2014). American Conspiracy Theories. Oxford: Oxford University Press. http://dx.doi.org/10.1093/acprof:oso/9780199351800.001.0001

Wood, M., Douglas, K., \& Sutton, R. (2012). Dead and alive: Beliefs in contradictory conspiracytheories. Social Psychological and Personality Science, 3(6), 767-773. http://dx.doi.org/10.1177/1948550611434786

Zook, M. (1996). The unorganized militia network: Conspiracies, computers and community. Berkeley Planning Journal, 11(1), 26-48.

\section{Notes}

${ }^{1} \mathrm{http}: / /$ www.patient.co.uk/

${ }^{2}$ Solon, O. (20 March, 2014). "How social media drives conspiracy theories.” Wired, Accessed June 2, 2015, http://www.wired.co.uk/news/archive/2014-03/20/how-conspiracy-theories-spread-on-fb

${ }^{3}$ Grossman, L. (2006, September 3). Conspiracy theories won't go away. Time, Retrieved from http://www.time.com/time/magazine/article/0,9171,1531304,00.html

${ }^{4}$ Source: http://en.wikipedia.org/wiki/Chemtrail_conspiracy_theory\#cite_note-currsci-1 (accessed on June 5, 2015).

\section{(cc) EY}

This work is licensed under a Creative Commons Attribution 3.0 License. 